\title{
Т.Н. Пермякова
}

Новосибирский государственный технический университет

\section{О компонентах содержательной структуры союзов}

Аннотация: В статье рассматривается вопрос о содержательной структуре союзов; о ее компонентах: категориальном значении, грамматическом значении и лексическом значении; о соотношении лексического и грамматического значения союзов.

The questions of the conjunctions' informative structure and its components are exposed in the article. This structure consists of categorial, grammatical and lexical meaning. The correlation of the conjunctions' lexical and grammatical meanings is discussed.

Ключевые слова: союз, содержательная структура, категориальное значение, грамматическое значение, лексическое значение.

Conjunction, informative structure, categorial meaning, grammatical meaning, lexical meaning.

УДК: 808.2-281-3.

Контактная информация: Новосибирск, пр. К. Маркса, 20. НГТУ, факультет гуманитарного образования. Тел. (383) 3460891. E-mail: uchi70@ mail.ru.

Поскольку союзы, подобно словам знаменательным, являются объектом лексикографического описания, то правомерным является вопрос об их содержательной структуре, в том числе о соотношении лексического и грамматического значения союзов. Тем более что относительно лексического статуса союза в лингвистике высказываются полярные точки зрения - от его полного отрицания [Кацнельсон, 2004]) до признания близости союзов к знаменательным словам [Рогожникова, 1974; Крейдлин, 1987 и др.].

При лексикографическом описании союзов лингвисты опираются на синтаксическую классификацию этих единиц и традиционно выделяют сочинительные союзы (соединительные, противительные, сопоставительные и т.д.) и подчинительные (изъяснительные, временные, сравнительные и т.д.). Между тем на сегодняшний день обоснованной семантической классификации союзов не существует, что, впрочем, неудивительно, поскольку ее создание тесно связано с определением лексического значения каждой единицы.

Поэтому цель нашей статьи - определить, какие компоненты должны входить в содержательную структуру союза.

Поскольку союз - хоть и незнаменательная часть речи, но имеет статус слова, поэтому мы вслед за Ю. И. Леденевым [Леденев, 1988], считаем, что содержательная структура союза, подобно знаменательным словам, включает обязательно три компонента: категориальное, грамматическое и лексическое значение.

Вопрос о категориальном значении - компоненте содержательной структуры слова, свойственном всем единицам данного лексико-грамматического класса последовательно разработан только для знаменательных частей речи. Категориальное значение союза - релятивность, или выражение отношений. На наш взгляд, релятивность - явление бинарное: с одной стороны, мы можем говорить 
о формальных отношениях (т.е. грамматических связях синтаксических единиц), с другой стороны - о смысловых отношениях, что связано с лексическим значением союза. Не случайно союзы в современной лингвистике часто называют релятивными (релятивный от лат. relativus - отношение, относительный), или реляционными, единицами [Ляпон, 1986], релятивами, которые репрезентуют особый тип значения: внутренняя сторона этих единиц содержит информацию об отношени и, имеющем двойственный характер. В сложном предложении союз эксплицирует связь между двумя событиями.

Таким образом, категориальное значение союза состоит в общем указании на наличие отношений между предикативными единицами или словами, выражающими свернутые пропозиции (в семантическом плане это отношения между событиями или ситуациями в отличие от предлогов).

Своеобразие содержательной структуры рассматриваемых лексем, как отмечается в литературе, состоит в ином, по сравнению с полнозначными словами, соотношении грамматического и лексического значений и, следовательно, в специфике каждого из этих компонентов. Этот вопрос остается дискуссионным до сих пор [Рогожникова, 1972, 1991; Черкасова, 1973; Крейдлин, Поливанова, 1987 и др.], потому что не имеют окончательного решения следующие вопросы: 1) что считать грамматическим, лексическим значением союзов; 2) как соотносятся друг с другом эти компоненты.

Интерпретация содержательной структуры знаменательного слова базируется на том, что доминирует лексическое значение. Однако, в содержательной структуре союзов, во-первых, грамматическое значение и лексическое значение до сих пор разграничиваются нечетко, во-вторых, распространена точка зрения, что доминирует грамматическое значение и при этом не определяется, что такое лексическое значение и грамматическое значение [Федоров, 1972; Черкасова, 1973 и др.].

Прежде всего определим, что же считать грамматическим значением, а что - лексическим значением союза.

«Лингвистический энциклопедический словарь» определяет грамматическое значение как «обобщенное, отвлеченное языковое значение, присущее ряду слов, словоформ, синтаксических конструкций и находящее свое регулярное (стандартное) выражение в грамматических формах» [Лопатин, 1998, с. 116]. Если под грамматическим значением в морфологии понимают общие значения слов как частей речи, а также частные значения словоформ и слов в целом, например, значения времени, лица, числа, рода, то в синтаксисе грамматическое значение определяется в зависимости от синтаксической единицы: в словосочетании и сложном предложении как разнообразные отношения компонентов этих единиц, а в простом предложении как «предикативность» [Белошапкова, 1967].

На наш взгляд, целесообразно интерпретировать грамматическое значение союза как выражение формальных отношений между предикативными единицами или внутри них (сочинение, подчинение и т.д.). Подчеркнем, что близкие идеи высказывались в работах ряда лингвистов [Пешковский, 1956; Федоров, 1972; Ширяев, 1986 и др.]. Как показывают А.М. Пешковский, Е.Н. Ширяев, различия между сочинением и подчинением как раз и заключается в их грамматических функциях: все подчинительные союзы выражают «подчиненность одного из связываемых компонентов другому»; сочинительные - «одинаковую отнесенность, в том числе и потенциальную, двух связываемых этим союзом компонентов к третьему» [Ширяев, 1986, с. 20]. А.К. Федоров также считает, что грамматическое значение рассматриваемых единиц проявляется в противопоставлении подчинительных и сочинительных союзов, и выделяет сочинительное (выражение союзом «некоторой автономности связываемых синтаксических единиц») и подчинительное (выражение союзом зависимости одной синтаксической единицы от другой) грамматическое значение союза. Существенным же признаком, отли- 
чающим подчинительные союзы от сочинительных, он считает «невозможность употребления их для связи однородных членов предложения» [Федоров, 1972, с. 10]. И самое главное, союз, как выражается А.Ф. Прияткина, является «конструктивной основой» [Прияткина, 1977] сложного предложения, он выражает формальные отношения; а также является главным, почти единственным выразителем характера связи частей, которая и составляет собственное значение сложного предложения [Черемисина, 1980].

Если признавать, что союз имеет только грамматическое значение, то это означает, что он выполняет только синтаксическую функцию - связь предикативных единиц или слов. Тогда между ними можно было бы поместить любую скрепу.

Сопоставим два высказывания с одинаковым лексическим наполнением предикативных единиц, которые различаются союзами, маркерами одной и той же синтаксической связи - сочинения, даже если они являются многофункциональными, например, ср.:

Май, и в поле ещче прохладно.

Май, а в поле ещзе прохладно.

При замене одного союза другим меняется семантика сложного предложения - причинно-следственная на значение несоответствия. Следовательно, даже такие полифункциональные союзы, как $\boldsymbol{u}$ и $\boldsymbol{a}$, вносят определенный вклад в смысловую структуру предложения Следовательно, в содержательной структуре союза есть лексический компонент.

По дефиниции В.П. Гака, лексическое значение - это «содержание слова, отображающее в сознании и закрепляющее в нем представление о предмете, свойстве, процессе, явлении и пр. Лексическое значение - продукт мыслительной деятельности человека, оно носит обобщенный характер» [Языкознание, 1998, с. 261]. Думается, что под этим «пр.» идет речь об отношениях, на которые говорящий указывает и с помощью союза, поскольку в конкретных актах речи в соответствии с отображаемой ситуацией говорящий делает выбор между союзами, а этот выбор возможен как раз вследствие наличия у каждой скрепы своего индивидуального значения. Это последнее и является лексическим значением, отличающим его от других слов [Литвин, 1987].

Таким образом, союзы, как и знаменательные слова, обладают и грамматическим, и лексическим значениями, хотя по сравнению со знаменательными словами имеют свои особенности.

Применительно к союзам вопрос, что считать лексическим значением, решается противоречиво. То, что Р.П. Рогожникова именует «частным грамматическим значением», т.е. «значением, присущим всем служебным словам одной и той же функциональной группы (для союзов - соединительные, разделительные, градационные, причинные и т.п. отношения)» [Рогожникова, 1977, с. 343], по мнению Е.Т. Черкасовой - «общее лексическое значение» [Черкасова, 1973, с. 8], присущее всем союзам одной функционально-смысловой группы. Кроме того, Е.Т. Черкасова выделяет и частные лексические значения, отличающие отдельный союз от других союзов той же функционально-смысловой группы. В одной из своих работ Р.П. Рогожникова уточняет, что лексическое и грамматическое значения служебных слов (союзов) очень тесно переплетены и считает, что «правильнее было бы назвать их лексико-грамматическими значениями» [Рогожникова, 1972, с. 345]. На наш взгляд, можно говорить об общем значении функционально-смысловой группы. Так же как и в знаменательных словах, в содержательной структуре союзов есть компонент (архисема), объединяющий союзы в одну функционально-смысловую группу, и есть компоненты (семы), отличающие союзы друг от друга.

В современной лингвистике вопрос о семной структуре союзов практически не изучается, и, соответственно, наука располагает пока лишь незначительными 
сведениями об этих «квантах» информации. Более детальное, подробное изучение семной структуры союзов, ее экспликация и есть задача современной лингвистики. В решении данной проблемы большую ценность имеет опыт Г.Е. Крейдлина [Крейдлин, 1994], который при семантической интерпретации многозначного предлога среди, описывает значение этого слова, выявляя семы.

Для примера рассмотрим группу причинных союзов. Ср.:

Он не выступил с докладом, потому что/так как заболел.

Он не выступил с докладом, благодаря тому что заболел.

Он не выступил с докладом, вследствие того что заболел.

Он не выступил с докладом, ибо заболел.

Он не выступил с докладом, коль скоро заболел.

Он не выступил с докладом, потому как заболел.

Все единицы данной группы союзов, с одной стороны, объединены общим макрокомпонентом - значением прямой реальной стимулирующей обусловленности широкого плана, иными словами, отчетливо выделяются два события (одно событие - посылка, основание (П1), второе - результат, вывод, (C1), и связь между ними квалифицируется как прямая реальная стимулирующая обусловленность. С другой стороны, скрепы в составе функционально-смысловой группы причинных союзов различаются семами. Так, говорящий выбирает тот или иной союз в соответствии со своими интенциями. Например, союз благодаря тому что говорящий употребляет, чтобы назвать благоприятствующую причину, союз вследствие того что - причину, непосредственно вызывающую результат. Вероятно, что и союзы коль скоро, потому что, так как, обозначая причинную зависимость, различаются какими-то компонентами лексического значения - семами ${ }^{1}$.

Итак, лексическим значением союза мы считаем его индивидуальное значение, реализуемое в высказывании и выявляемое на фоне других союзов данной функционально-смысловой группы. На наш взгляд, лексический компонент союза можно сравнить с «многослойным пирогом», состоящим из нескольких семантических «слоев», представленных различными семами и стилистическим компонентом.

Таким образом, мы можем сделать следующие выводы.

1. Союзы являются лексическими единицами и поэтому имеют, как и знаменательные слова, содержательную структуру, которая включает три обязательные компонента: категориальное значение, грамматическое и лексическое значение.

2. Категориальное значение союза - релятивность, или выражение отношений между событиями или ситуациями.

3. Грамматическое значение союза - это выражение формальных отношений равноправия (сочинения) или зависимости (подчинения) между частями сложного или простого предложения.

4. Лексическое значение союза - это его индивидуальное значение, представляющее собой некую совокупность сем, внутри которых можно выделить, помимо интегральной, семы, отличающие один союз от другого в рамках одной функционально-смысловой группы.

\section{Литература}

Белошапкова В.А. Сложное предложение в современном русском языке. M., 1967.

Кацнельсон С.Д. Содержание слова, значение и обозначение / Под общ. ред. В.М. Жирмунского, М.М. Гухман, С.Д. Кацнельсона. М., 2004. С. 3-10.

${ }^{1}$ Более подробный анализ структуры лексического значения союза мы проведем в другой статье. 
Крейдлин Г.Е. Метафора семантических пространств и значение предлога // Вопросы языкознания. 1994. № 5. С. 19-27.

Крейдлин Г.Е., Поливанова А.К. О лексикографическом описании служебных слов русского языка // Вопросы языкознания. М., 1987. № 1. С. 106-120.

Леденев Ю.И. Неполнозначные слова. Ставрополь, 1988.

Литвин Ф.А. Полисемия и омонимия служебных слов // Служебные слова. Новосибирск, 1987.

Ляпон М.В. Смысловая структура сложного предложения и текст. К типологии внутритекстовых отношений. М., 1986.

Пешковский А.М. Русский синтаксис в научном освещении. М., 1956.

Прияткина А.Ф. Союзные конструкции в простом предложении. М., 1977.

Рогожникова Р.П. Словарь эквивалентов слова: наречные, служебные, модальные единства. М., 1991.

Рогожникова Р.П. Об эквивалентах слова в русском языке // Вопросы языкознания. М., 1977. № 3. С. 110-116.

Федоров А.К. Система подчинительных союзов в современном русском языке. М., 1972.

Черемисина М.И. О содержании понятия «предикативность» в синтаксисе сложного предложения // Полипредикативные конструкции и их морфологическая база. Новосибирск, 1980. С. 154-181.

Черкасова Е.Т. Русские союзы неместоименного происхождения. М., 1973.

Ширяев Е.Н. Бессоюзное сложное предложение в современном русском языке. М., 1986.

Языкознание. Большой энциклопедический словарь / Гл. ред. В.Н. Ярцева. M., 1998. 